\title{
Painful temporomandibular disorder, sleep bruxism, anxiety symptoms and subjective sleep quality among military firefighters with frequent episodic tension-type headache. A controlled study.
}

\author{
Desordens temporomandibulares dolorosas, bruxismo do sono, sintomas de ansiedade \\ e qualidade subjetiva do sono em bombeiros militares com cefaleia do tipo tensional \\ episódica frequente. Estudo controlado.
}

Bianca de Araújo Wagner', Pedro Ferreira Moreira Filho²

\begin{abstract}
Objective: To investigate associations of temporomandibular disorders (TMDs), bruxism, anxiety and sleep quality among military firefighters with frequent episodic tension-type headache (FETTH). Methods: The sample comprised two groups (80 individuals): controls (mean age 35.2 years) and study group (mean age 38.5 years). Headache was diagnosed in accordance with the ICHD-III. The Research Diagnostic Criteria for TMDs were used to classify the TMDs; bruxism was diagnosed in accordance with the International Classification of Sleep Disorders; anxiety was classified using the Beck Anxiety Inventory; and sleep quality was assessed using the Pittsburgh Sleep Quality Index. In the statistical models, we used a significance level of 95\%. Results: Associations were found between participants with FETTH and TMDs ( $p$ <.001) and anxiety ( $p=0.002)$. Poor quality of sleep $(p=0.687)$ and bruxism $(p=0.670)$ were not risk factors. Conclusion: The study found that TMDs and anxiety among firefighters were associated with FETTH.
\end{abstract}

Keywords: tension-type headache; temporomandibular joint disorders; bruxism; surveys and questionnaires.

RESUMO

Objetivo: Investigar associações de distúrbios temporomandibulares (DTM), bruxismo, ansiedade e qualidade subjetiva do sono entre bombeiros militares com cefaleia do tipo tensional episódica frequente (CTTEF). Método: Aamostra consistiu em dois grupos com 80 indivíduos cada: controles (idade média 35,2 anos) e grupo de estudo (idade média 38,5 anos). A dor de cabeça foi diagnosticada de acordo com a Classificação Internacional de Cefaleias, $3^{a}$ edição. Os critérios de diagnóstico de pesquisa para DTM (RDC / TMD) foram utilizados para classificar DTM; o bruxismo foi diagnosticado de acordo com a Classificação Internacional de Distúrbios do Sono; a ansiedade foi classificada usando o Inventário de Ansiedade Beck; e a qualidade do sono foi avaliada usando o Índice de Qualidade do Sono de Pittsburgh (PSQI). Nos modelos estatísticos utilizamos um nível de significância de 95\%. Resultados: Foram encontradas associações entre indivíduos com CTTEF e presença de DTM ( $p<0,001)$ e ansiedade $(p=0,002)$. A baixa qualidade do sono $(p=0,687)$ e o bruxismo $(p=0,670)$ não foram fatores de risco para CTTEF. Conclusão: 0 estudo verificou que DTM e ansiedade entre os bombeiros estavam associados a CTTEF, mas a qualidade subjetiva do sono e o bruxismo não foram fatores de risco.

Palavras-chave: cefaleia do tipo tensional; transtornos da articulação temporomandibular; bruxismo;inquéritos e questionários.

The serious political, economic and moral crisis that affects Brazil, especially the state of Rio de Janeiro, with violence and neglect of public institutions, is reflected in the life and work of our population.

Studies have indicated that the activities of military firefighters have direct correlations with occupational stress, high risk of back injuries, dangerous working conditions, complaints of anxiety and depression, irregular work shifts and consequent changes in sleep patterns ${ }^{1,2,3}$.

Anxiety symptoms and changes in sleep patterns have been correlated with the presence of headaches and temporomandibular disorders (TMDs) $)^{4,5,6,7}$. Some studies have described associations of this nature in the profession of military firefighter ${ }^{1-3}$. Also, in these professionals, deficiencies in

'Universidade Federal Fluminense, Pós-Graduação em Neurociências, Niterói RJ, Brasil;

¿Universidade Federal Fluminense, Departamento de Neurologia, Niterói RJ, Brasil.

Correspondence: Bianca de Araújo Wagner; Praça Carlos Gardel, 32 / apto 301; 22790-460 Rio de Janeiro RJ, Brasil. E-mail: biancawagner@gmail.com Conflict of interest: There is no conflict of interest to declare.

Received 19 August 2017; Received in final form 14 February 2018; Accepted 26 February 2018. 
sleep quality have been correlated with work accidents and thus represent a risk to their safety ${ }^{8}$.

Frequent episodic tension-type headache (FETTH) is described as frequent episodes of headache that are typically bilateral, of a pressing or tightening quality and of mild to moderate intensity. They may last for periods of minutes to days. The pain does not worsen with routine physical activity and is not associated with nausea, but photophobia or phonophobia may be present and there may be at least 10 episodes of headache occurring on 1 to 14 days per month, which are repeated, on average, for more than three months $(\geq 12 \text { days and }<180 \text { days per year })^{9}$.

Pericranial myofascial nociception may be important in the pathophysiology of FETTH, whereas sensitization of central nociceptive pathways seems to be responsible for conversion of episodic headache to chronic tensiontype headache ${ }^{10}$.

In spite of the high frequency of tension-type headaches in the population, a low demand for medical attention has been registered ${ }^{9}$. For this reason, few articles have discussed associations of symptoms in episodic cases. Although the interweaving of symptoms makes diagnosis difficult ${ }^{11}$, the presence of oral parafunctional habits, that are inappropriate for treatment by analgesic drugs, suggests that more training in the field of headache and orofacial pain is required at primary healthcare units $^{12}$.

Headache is also a frequent complaint among patients with TMDs ${ }^{10,13,14,15,16}$. According to the American Academy of Orofacial Pain, TMD is defined as a set of disorders involving the masticatory muscles, temporomandibular joint and associated structures ${ }^{17}$.

The etiology of TMDs is considered to be multifactorial and its natural course remains unclear. It is believed that there are risk factors that contribute to its onset or to the perpetuation of the pain ${ }^{17}$. One of these factors is sleep bruxism, which is defined as repetitive jaw-muscle activity characterized by clenching or grinding of the teeth and/or by bracing or thrusting of the mandible ${ }^{18}$.

Some studies have found an interaction between the presence of primary headaches and TMDs ${ }^{10,13,15,16}$, but few studies have been conducted on their relationship to frequent episodic tension-type headache ${ }^{14}$. None have been conducted among military firefighters.

All these symptoms and complaints are common. Patient education, behavioral intervention, drugs, individually fabricated occlusal splint therapy, physical therapies, postural training and exercises are examples of available treatment options. Evidence-based dentistry advocates treatment through multidisciplinary teams (doctors, dentists, physiotherapists and psychologists) working in their specific areas, with conservative proposals ${ }^{17}$.

The objective of our study was to evaluate associations of painful TMD, sleep bruxism, subjective sleep quality and anxiety symptoms among military firefighters with and without FETTH.

This study was approved by the Ethics Committee for Research on Human Beings of the Medical School of the Fluminense Federal University, and the approval was filed under number \#1341316.

The study was conducted within the Military Firefighters' Department of the State of Rio de Janeiro, over the period from December 1, 2015, to April 26, 2016.

\section{METHODS}

A total of 285 individuals between the ages of 18 and 55 years were examined and 125 were excluded through the following criteria: loss of more than two posterior teeth, except third molars $(\mathrm{n}=11)$; presence of a total or partial prosthesis $(n=24)$; presence of toothache or neuropathic pain $(n=3)$; continuous treatment of psychiatric disorders, major rheumatological, neurological or chronic pain syndrome $(n=31)$; presence of other headaches $(n=42)$; diagnosis or signs and symptoms compatible with other sleep disorders $(n=5)$; and impossibility of regular monitoring because of not attending all assessment visits $(\mathrm{n}=9)$.

The sample was made up through spontaneous demand from the military firefighters who sought treatment at the Orofacial Pain Clinic at the General Command Headquarters of the Military Fire Brigade of the State of Rio de Janeiro.Each of the 160 individuals (mean age 36.9 years; standard deviation \pm 9.9 years; $52.5 \%$ females and $47.5 \%$ males) who took part in the survey read and signed a free and informed consent form. There was no external financing source for this study.

A standardized protocol test was applied to all patients, using the following diagnostic tools: anamnesis, medical and dental history and physical examination in accordance with standardized clinical records. Through this, the main complaint, pain characteristics (location, intensity, quality, duration, worsening period, mitigating and aggravating factors), presence of headache and pain in other parts of the body and the patient's medical history were detailed.

The evaluation of FETTHs was performed by a single neurologist through a questionnaire containing objective questions that were in line with the diagnostic criteria established through the International Classification of Headache Disorders - III, $3^{\text {rd }}$ edition (beta version) ${ }^{9}$.

The individuals diagnosed with FETTH presented with: frequent episodes of headache, typically bilateral, pressing or tightening in quality and of mild to moderate intensity, lasting minutes to days. The pain did not worsen with routine physical activity and was not associated with nausea, but photophobia or phonophobia may have been present ${ }^{9}$. 


\section{TMD assessment}

The Research Diagnostic Criteria for Temporomandibular Disorders (RDC/TMD) $)^{19}$ Portuguese version ${ }^{20}$; were applied to classify TMDs. The RDC/TMD is a standardized system that can be used to classify the most common subtypes of TMD through a questionnaire and a physical examination. Based on Axis I of the RDC/TMD, patients were classified into: group I (muscle disorders); group II (disc displacements) and group III (arthralgia, arthritis and arthrosis). Subsequently, they were divided into two groups. Individuals with complaints of painful TMD (group I: myofascial pain TMD or myofascial pain TMD with limited opening; and/or group III: temporomandibular joint arthralgia and/or osteoarthritis), which became the study group; and the control group who had no complaints of painful TMD (only group II diagnosis: disc displacement with or without reduction or absence of TMD; no diagnoses of groups I, II or III).

During the evaluation of masticatory muscle sensitivity, the participants of the control group confirmed that the pain caused was similar to the pain reported by the patients in the study group ${ }^{21}$. Muscle examination (masseter and temporal) and joint capsules to assess sensitivity were done manually. A standard pressure of $1 \mathrm{~kg}$ was applied to the extra-oral muscles and $0.5 \mathrm{~kg}$ to the joints. ${ }^{20}$ The pressure was calibrated using a digital electronic scale. The balance was set to zero and the digital pressure of $1 \mathrm{~kg}$ was placed on the plate. The individuals who reported sensitivity in masticatory muscles and joint capsules with intensity of at least 3 in the last month were considered patients with painful TMD.

\section{Assessment of sleep bruxism}

The diagnosis of sleep bruxism was made in two stages: application of a questionnaire consisting of seven objective questions in accordance with the criteria of the International Classification of Sleep Disorders, $3^{\text {rd }}$ edition ${ }^{22}$; and a physical examination. This assessment consisted of a systematic evaluation of signs and symptoms of sleep bruxism in terms of the following:

1) Frequency of days of self-reported sleep bruxism, which was evaluated through five possible choices: (0) none of the time; (1) < 1 night per month; (2) 1-3 nights per month; (3) 1-3 nights per week; (4) 4-7 nights per week ${ }^{23}$.

2) The questionnaire for sleep bruxism, based on the International Classification of Sleep Disorders, $3^{\text {rd }}$ edition, which included three questions about the presence or absence of transient morning jaw muscle pain or fatigue, temporal headache, and jaw locking upon awakening ${ }^{22}$.

3) Assessment of abnormal tooth wear, which was observed through an ordinal scale of five points. The incisor, canine and last molar present in the fourth dental quadrant were inspected. Tooth wear was classified on a tooth-by-tooth basis using an ordinal scale of five points ${ }^{24}$.

Patients were considered to have sleep bruxism when it was self-reported on more than four nights a week and, in addition, these patients presented with: 1) incidences of abnormal tooth wear; or 2) incidences of transient morning jaw muscle pain or fatigue. For a diagnosis of sleep bruxism to be made, it would need to be impossible to explain the jaw muscle activity in terms of any other current sleep disorder, medical or neurological disorder, medication use, substance use disorder, or use of selective serotonin reuptake inhibitors ${ }^{25}$.

\section{Assessment of anxiety symptoms}

Anxiety symptoms were assessed using the Beck Anxiety Inventory. This instrument features 21 items that somatically, emotionally and cognitively reflect anxietysymptoms ${ }^{26}$. It is used to measure the severity of an individual's anxiety. The instrument consists of a self-report questionnaire with 21 multiple-choice questions about how the individual has felt over the last week, expressed in terms of common anxiety symptoms. Each symptom item has four possible response options, as follows, with the corresponding scores: not at all (0); mildly but it didn't bother me much (1); moderately, and it wasn't pleasant at times (2); and severely, and it bothered me a lot (3). The values for each item are summed to produce a total score for all 21 symptoms that can range from 0-63 points, and higher values mean higher levels of anxiety symptoms.

\section{Assessment using the Pittsburgh Sleep Quality Index}

The Pittsburgh Sleep Quality Index (PSQI) provides a combination of quantitative and qualitative information on sleep $^{27}$. There are 19 items in the PSQI, and these provide estimates of the quality and duration of sleep, sleep onset, frequencies of various sleep-related disturbances and daytime sequelae. It yields seven "components", which can be summed to give an overall score ranging from $0-21$, in which higher values represent a greater disturbance of sleep. Individuals can thus be classified as having the following: good sleep (scores of 0-4), bad sleep (scores of 5-10) and the presence of a sleep disturbance (scores $>10$ ).

The statistical analysis was conducted using the SPSS version 19. A logistic regression model was used to calculate the odds ratios (OR) as a relative measurement of risk.

Descriptive statistics and frequency counts were used to characterize the sample. Quantitative outcomes (age, Beck Anxiety Inventory and PSQI) are presented as means and standard deviations (SD), along with the distribution according to sex. For the ORs, and in correlations and tables, a significance level of $95 \%$ was used.

\section{RESULTS}

Two groups were formed, divided according to the presence of FETTH complaints, with 80 individuals in each group. The control group (FETTH-free) comprised 44 men (55\%) and 
36 women (45\%), mean age 35.2 years (range $19-55$ years); the majority $(54 \% \mathrm{n}=43)$ had completed high school. The study group (FETTH patients) comprised 48 women (60\%) and 32 men (40\%), mean age 38.5 years (range 18-55 years); $58.8 \%$ ( $\mathrm{n}=47$ ) had completed undergraduate education (Table 1).

The presence of painful TMD was higher in the study group $(76.25 \% ; n=61)$. Headache complaints were more common among women $(60.0 \% ; n=48)$. The prevalence of sleep bruxism was $16.0 \%(n=26)$ and the activity level was higher in the study group $(\mathrm{n}=16)$.

Table 2 shows the interaction between painful TMD and FETTH (OR = 26.4; 95\% confidence interval, CI: 10.4-64.6; $\mathrm{p}<0.001)$. The presence of sleep bruxism did not represent a risk of occurrence of FETTH $(\mathrm{OR}=0.7$; 95\% CI: 2.0-2.5; $\mathrm{p}=0.670$ ).

The mean PSQI components were slightly higher in the study group (PSQI = 5.3) than among the controls (PSQI = 4.5). However, we did not find any significance in these data ( $p=0.687$ ), indicating that sleep quality assessments did not show increased risk of FETTH.

The individuals in the study group had more anxiety symptoms $(\mathrm{p}=0.002)$.

Individuals with sleep bruxism (Table 3 ) had more complaints of painful TMD ( $p=0.012)$.

Table 1. Distribution of the sample by the presence of FETTH n (\%).

\begin{tabular}{|c|c|c|c|}
\hline \multirow{2}{*}{ Variables } & Total & Absence of FETTH & Presence of FETTH \\
\hline & $160(100)$ & $80(100)$ & $80(100)$ \\
\hline Mean \pm SD (range) & $36.8 \pm 9.9(18-55)$ & $35.2 \pm 10.0(19-55)$ & $38.5 \pm 9.7(18-55)$ \\
\hline \multicolumn{4}{|l|}{ Gender } \\
\hline Female & $84(52.5)$ & $36(45.0)$ & $48(60.0)$ \\
\hline Male & $76(47.5)$ & $44(55.0)$ & $32(40.0)$ \\
\hline \multicolumn{4}{|l|}{ Educational level } \\
\hline Undergraduate level & $84(52.5)$ & $37(46.3)$ & $47(58.8)$ \\
\hline High School & $76(47.5)$ & $43(53.7)$ & $33(41.2)$ \\
\hline Sleep Bruxism & $26(16.0)$ & $10(12.5)$ & $16(20)$ \\
\hline Painful TMD & $70(100)$ & $9(11.25)$ & $61(76.25)$ \\
\hline
\end{tabular}

FETTH: frequent episodic tension-type headache.

Table 2. Analysis of results.

\begin{tabular}{|c|c|c|c|c|}
\hline Variables & Study Group & Control Group & Total & Odds Ratio \\
\hline Painful TMD diagnoses & Presence of FETTH n (\%) & Absence FETTH n (\%) & Total $n=160$ & OR $(95 \% \mathrm{Cl})$ \\
\hline Absence of TMD & $19(21.0 \%)$ & $71(79.0 \%)$ & 90 & Reference \\
\hline \multirow[t]{2}{*}{ Presence of TMD } & $61(87.0 \%)$ & $9(13.0 \%)$ & 70 & $26.4(10.4 ; 64.6)$ \\
\hline & & & & $p<0.001$ \\
\hline \multicolumn{5}{|l|}{ Sleep bruxism } \\
\hline Absence & $64(48.0 \%)$ & $70(52.0 \%)$ & 134 & Reference \\
\hline \multirow[t]{2}{*}{ Presence } & $16(62.0 \%)$ & $10(38.0 \%)$ & 26 & $0.7(0.2 ; 2.5)$ \\
\hline & & & & $p=0.670$ \\
\hline \multicolumn{5}{|l|}{ Mean PSQI } \\
\hline Good sleepers & $33(41.5 \%)$ & $31(38.5 \%)$ & 64 & Reference \\
\hline Bad sleepers & $42(52.5 \%)$ & $46(57.5 \%)$ & 88 & $1.8(0.41 ; 8.1)$ \\
\hline \multirow[t]{3}{*}{ Sleep disturbance } & $5(6.0 \%)$ & $3(4.0 \%)$ & 8 & \\
\hline & & & & $p=0.687$ \\
\hline & Mean PSQI = 5.3 & Mean PSQI = 4.5 & & \\
\hline \multicolumn{5}{|l|}{ Beck anxiety inventory } \\
\hline Minimum & $33(41.3 \%)$ & $61(76.3 \%)$ & 94 & Reference \\
\hline Light & $32(40.0 \%)$ & $16(20.0 \%)$ & 48 & $1.000(0.1 ; 1.9)$ \\
\hline Moderate & $13(16.2 \%)$ & $2(2.5 \%)$ & 15 & $0.3(0.0 ; 5.1)$ \\
\hline \multirow[t]{2}{*}{ Severe } & $2(2.5 \%)$ & $1(1.2 \%)$ & 3 & \\
\hline & & & & $p=0.002$ \\
\hline
\end{tabular}

FETTH: frequent episodic tension-type headache;TMD: temporomandibular disorders; PSQI: Pittsburgh Sleep Quality Index; Cl: confidence interval. 
Table 3. Association of painful TMD diagnoses with sleep bruxism.

\begin{tabular}{lccc}
\hline TMD Diagnoses n (\%) & $\begin{array}{c}\text { Presence } \\
\text { of SB }\end{array}$ & $\begin{array}{c}\text { Absence of } \\
\text { SB }\end{array}$ & $\begin{array}{c}\text { Odds ratio } \\
(95 \% \mathrm{Cl})\end{array}$ \\
\hline Painful TMD n (\%) & $17(66.4)$ & $53(39.6)$ & Reference \\
No Painful TMD n (\%) & $9(34.6)$ & $81(60.4)$ & $2.9(1.2-6.9)$ \\
\hline
\end{tabular}

TMD: temporomandibular disorders; SB: sleep bruxism; Cl: confidence interval.

\section{DISCUSSION}

This study is the first to assess the presence of painful TMD, sleep bruxism, anxiety symptoms and subjective sleep quality among military firefighters with FETTH.

The presence of FETTH was shown to be directly linked to the presence of painful TMD symptoms $(\mathrm{p}<0.001)$.

Some studies on the interactions between primary headache and the presence of TMD symptoms ${ }^{10,14,15,16,17}$ have shown that despite methodological differences (sample, headache classification and use of non-standardized questionnaires), this association was greater when there was pain in the masticatory muscles.

The conditions relating to primary headaches have been little studied among military firefighters. In this specific group, symptoms relating to insomnia, anxiety, depression and low back pain were directly associated with loss of quality of life and occurrences of work accidents ${ }^{1,2,3,8}$.

There are significant clinical overlaps between some painful TMDs and headache conditions that may hamper the diagnostic process and treatment. The important pain mechanisms contributing to the close association and complex relationship between TMDs and headache disorders include the following: processes of peripheral and central sensitization that take place in similar anatomical areas; possible impairment of the descending modulatory pain pathways; and the processes of reporting pain. In addition, clinical examinations do not always provide distinguishing information to differentiate between headaches and $\mathrm{TMD}^{11}$.

When peripheral alterations persist and other external factors such as emotional disturbances, stress and parafunctional habits are associated, changes to the central nervous system may occur. These changes to the conduction system and pain processing are called central sensitization ${ }^{28}$.

The presence of sleep bruxism (Table 3) was higher among individuals with complaints of painful TMD ( $p=0.012)$. This probably occurred because of the concomitant presence of sleep bruxism and clenching of teeth during wakefulness, although ascertaining this relationship was not an objective of the present study.

When sleep bruxism and daytime tooth clenching occur separately, they increase the risk of painful TMD symptoms. When they act simultaneously, the risk is even greater ${ }^{29}$. A systematic review has shown that sleep bruxism may be associated with myofascial pain, arthralgia and pathological conditions of joints, such as disc displacement and joint noises. Although the evidence is currently not conclusive and does not provide information according to the type of bruxism (sleep and/or waking bruxism), it is possible to suggest that bruxism would be associated with TMDs ${ }^{30}$.

It was found that sleep bruxism alone did not increase the risk of any primary headache, but when it was associated with a painful TMD, the odds of having chronic migraine, episodic migraine and episodic tension-type headache were significantly increased ${ }^{16}$.

Sleep and headache are closely related. Insufficient sleep may increase the risk of headache in a general manner; it may trigger headache and may also reduce pain thresholds ${ }^{31}$.

The anxiety symptoms observed increased the risk of FETTH ( $p=0.002$ ), while the subjective quality of sleep measured by the PSQI was not shown to be a risk factor $(p=0.687)$.

The anxiety symptoms observed in individuals with FETTH and TMD are in agreement with other studies ${ }^{4,5,6,31}$.

Sleep and pain perception are two phylogenetically wellconserved functions, strictly influenced by environmental and psychological factors, and are able to interact reciprocally both in physiological and pathological situations ${ }^{32}$.

In a study on sleep among tension-type headache patients, it was observed that these patients presented with more anxiety, insomnia and fatigue during the day and lower subjective quality of sleep than did healthy controls, despite presenting with a normal duration of sleep in diaries and in polysomnographic examinations. It has been proposed that, on average, these individuals need more sleep time than required by healthy controls ${ }^{33}$.

There was a significant association between severe sleep disturbances and primary headache, and this was most pronounced for those with chronic headache ${ }^{4}$.

The study had some limitations. The sample consisted of patients who sought treatment for TMD and the results are not representative of the general population. Laboratory sleep assessment is required to establish a definitive diagnosis of sleep bruxism; but for large samples it is expensive and inaccessible.

The study's methodology had important strengths. Headache and TMD were diagnosed and classified following the "gold standard" of the $\mathrm{RDC} / \mathrm{TMD}^{19}$ and International Classification of Headache Disorders - III'.

In conclusion, based on the data of this study, an association between the presence of painful TMD complaints and subjective anxiety symptoms was found among individuals with FETTH.

Sleep quality assessments and the presence of sleep bruxism without painful TMD complaints did not increase the risk of FETTH.

\section{Acknowledgments}

We thank the Military Fire Brigade of the State of Rio de Janeiro for its support. 
1. Lusa S, Miranda H, Luukkonen R, Punakallio A. Sleep disturbances predict long-term changes in low back pain among Finnish firefighters: 13-year follow-up study. Int Arch Occup Environ Health. 2015; 88 (3):369-379. https://doi.org/10.1007/s00420-014-0968-z

2. Marconato RS, Monteiro M I. Pain, health perception and sleep: impact on the quality of life of firefighters/rescue professionals. Rev Lat Am Enfermagem. 2015; 23(6):991-9. https://doi.org/10.1590/0104-1169.0563.2641

3. Punakallio A, Lusa S, Luukkonen R,Airila A, Leino-Arjas P. Musculoskeletal pain and depressive symptoms as predictors of trajectories in work ability among Finnish firefighters at 13-year follow-up.J Occup Environ Med. 2014;56(4):367-75. https://doi.org/10.1097/JOM.0000000000000139

4. Vazquez- Delgado E, Schmidt JE, Carlson CR, DeLeeuw Rd, Okeson JP. Psychological and sleep quality differences between chronic daily headache and temporomandibular disorders patients. Cephalalgia. 2004; 24 (6):446-54. https://doi.org/10.1111/j.1468-2982.2004.00698.x

5. Reiter S, Emodi - Perlman A, Goldsmith C, Friedman-Rubin P, Wincur E. Comorbidity between depression and anxiety in patients with temporomandibular disorders according to the research diagnostic criteria for temporomandibular disorders. J Oral Facial Pain Headache. 2015; 29 (2):135-43. https://doi.org/10.11607/ofph.1297

6. Lampl C, Thomas H, Tassorelli C, et al. Headache, depression and anxiety: associations in the Eurolight project.J Headache Pain. 2016; 17(1):59.https://doi.org/10.1186/s10194-016-0649-2

7. Rener-Sitar K, John MT, Pusalavidyasagar SS, Bandyopadhyay D, Schiffman EL. Sleep quality in temporomandibular disorder cases. Sleep Med. 2016; 25:105-12. https://doi.org/10.1016/j.sleep.2016.06.031

8. Barger LK, Rajaratnam SM, Wang W, et al. Common sleep disorders increase risk of motor vehicle crashes and adverse health outcomes in firefighters. J Clin Sleep Med. 2015;11(3):233-40. https://doi.org/10.5664/jcsm.4534

9. Headache Classification Committee of the International Headache Society. The International Classification of Headache Disorders, 3rd edition (beta version). Cephalalgia. 2013; 33 (9):629-808. https://doi.org/10.1177/0333102413485658

10. Graff-Radford SB. Temporomandibular disorders and headache. Dent Clin North Am. 2007; 51 (1):129-44.https://doi.org/10.1016/j.cden.2006.09.005

11. Conti PC, Costa YM, Gonçalves DA, Svensson P. Headaches and myofascial temporomandibular disorders: overlapping entities, separate managements? J Oral Rehabil. 2016; 43 (9):702-15. https://doi.org/10.1111/joor.12410

12. Tomaz-Morais JF, Lucena LB, Mota IA, et al. Temporomandibular disorder is more prevalent among patients with primary headaches in a tertiary outpatient clinic. Arq Neuropsiquiatr. 2015; 73 (11):913-7. https://doi.org/10.1590/0004-282X20150145

13. Ballegaard V, Thede-Schmidt-Hansen P, Svensson P, Jensen R. Are headache and temporomandibular disorders related? A blinded study. Cephalalgia. 2008; 28(8): 832-41. https://doi.org/10.1111/j.1468-2982.2008.01597x

14. Troeltzsch M, Cronin RJ, Brodine AH, Frakenberger R, Messlinger K. Prevalence and association of headaches, temporomandibular disorders, and occlusal interferences. J Prosthet Dent. 2011; 105 (6): 410-7. https://doi.org/10.1016/S0022-3913(11)

15. Glaros AG, Urban D, Locke J. Headache and temporomandibular disorders: evidence for diagnostic and behavioural overlap. Cephalalgia. 2007; 27(6):542-9. https://doi.org/10.1111/j.1468-2982.2007.01325.x

16. Fernandes G, Franco AL, Gonçalves DA, Speciali JG, Bigal ME, Camparis CM. Temporomandibular disorders, sleep bruxism, and primary headaches are mutually associated. J Orofac Pain. 2013; 27(1):14-20. https://doi.org/10.11607/jop.921
17. Leeuw R. Orofacial pain: guidelines for assessment, diagnosis, and management. 4th ed. Chicago: Quintessence; 2008.

18. Lobbezoo F, Ahlberg J, Glaros AG, et al. Bruxism defined and graded: an international consensus. J Oral Rehabil. 2013; 40(1):2-4. https://doi.org/10.1111/joor.12011

19. Dworkin SF, LeResche L. Research diagnostic criteria for temporomandibular disorders: review, criteria, examinations and specifications, critique.J Craniomandib Disord. 1992; 6(4):301-55.

20. Pereira Júnior FJ, Favilla EE, Dworkin S, Huggins K. Critérios de diagnóstico para pesquisa das disfunções temporomandibulares (RDC/TMD): tradução oficial para a língua portuguesa.J Bras Clin Odontol Integ. 2004; 8(47):384-95.

21. Schiffman EL, Ohrbach R, Truelove EL, et al. The research diagnostic for temporomandibular disorders. V: methods used to establish and validate revised Axis I diagnostic algorithms. J Orofac Pain. 2010; 24(1):63-78.

22. American Academy of Sleep Medicine. International classification of sleep disorders. 3rd ed. Darien: American Academy of Sleep Medicine; 2014.

23. Stuginski-Barbosa J, Porporatti AL, Costa YM, Svensson P, Conti PC. Agreement of the International Classification of Sleep Disorders Criteria with polysomnography for sleep bruxism diagnosis: a preliminary study.J Prosthet Dent. 2017; 117(1):61-6. https://doi.org/10.1016/j.prosdent.2016.01.035

24. Lobbezoo F, Naeije M. A reliability study of clinical tooth wear measurements. J Prosthet Dent. 2001; 86(6):597-602. https://doi.org/10.1067/mpr.2001.118892

25. Lobbezoo F, Denderen RJ, Verheij JG, Naeije M. Reports of SSRIassociated bruxism in the family physician's office. J Orofac Pain. 2001; 15(4):340-6.

26. Beck AT, Epstein N, Brown G, Steer RA. An inventory for measuring clinical anxiety: psychometric properties. J Consult Clin Psychol. 1988; 56 (6):893-7. https://doi.org/10.1037/0022-006X.56.6.893

27. Buysse DJ, Reynolds CF 3rd, Monk TH, Berman SR, Kupfer DJ. The Pittsburgh Sleep Quality Index: a new instrument for psychiatric practice and research. Psychiatry Res. 1989; 28 (2):193-213. https://doi.org/10.1016/0165-1781(89)90047-4

28. Woolf CJ. Central sensitization: implications for the diagnosis and treatment of pain. Pain. 2011;152:2-15. https://doi.org/10.1016/j.pain.2010.09.030

29. Sierwald I, John MT, Schierz O, et al. Association of temporomandibular disorder pain with awake and sleep bruxism in adults. J Orofac Orthop. 2015; 76(4):305-17. https://doi.org/10.1007/s00056-015-0293-5 PMID: 26123732

30. Silva A, Peña-Durán C, Tobar-Reyes J, Frugone-Zambra R. Sleep and awake bruxism in adults and its relationship with temporomandibular disorders: A systematic review from 2003 to 2014. Acta Odontol Scand. 2017; 75(1):36-58. https://doi.org/10.1080/00016357.2016.1247465

31. Smitherman TA, Davis RE, Walters AB, Young J, Houle TT. Anxiety sensitivity and headache: diagnostic differences, impact, and relations with perceived headache triggers. Cephalalgia. 2015; 35(8):710-21. https://doi.org/10.1177/0333102414557840

32. Lovati C, D'Amico D, Raimondi E, Mariani C, Bertora P. Sleep and headache: a bidirectional relationship. Expert Rev Neurother. 2010; 10(1):105-17. https://doi.org/10.1586/ern.09.135

33. Engstrøm M, Hagen K, Bjørk MH, Stovner LJ, Sand T. Sleep quality and arousal in migraine and tension-type headache: the headachesleep study. Acta Neurol Scand Suppl. 2014; 129(198):47-54. https://doi.org/10.1111/ane.12237 